\title{
Neoplasia Cervical en Mujeres con Citología Clase II
}

\author{
LIGA SANTANDEREANA DE LUCHA CONTRA EL CANCER \\ BUCARAMANGA
}

\author{
Dr. Pedro Ignacio Silva Pérez*
}

\section{RESUMEN}

Se estudiaron 355 mujeres con citología clase II. A todas se les practicó colposcopia y a 177 se les tomó biopsia de cérvix por presentar imágenes sugestivas de neoplasia cervical. Esta sospecha se confirmó en 118, distribuidas así: 69 NIC I, 35 NIC II, 11 NIC III y 3 carcinomas invasores. Subdivididas en 3 grupos, la incidencia de neoplasia cervical fue de $23 \%$ para la citología PAP II simple, 37\% para el PAP II inflamatorio o hemorrágico y $66 \%$ para el PAP II con atipias severas.

Se revisó la fecha de la última citología negativa (PAP II) en las pacientes a quienes se les diagnosticó NIC III o carcinoma invasor en los últimos 3 $1 / 2$ años (441 casos). $47 \%$ tuvieron citología negativa en los últimos 2 años y $38 \%$ no se habían tomado antes una citología.

La citología clase II debe tenerse en cuenta en los programas de prevención y diagnóstico precoz del cáncer de cérvix y debe manejarse con protocolo diferente a la citología negativa clase I.

\section{INTRODUCCION}

En Colombia el carcinoma de cuello uterino sigue siendo una neoplasia muy frecuente y conti-

Ginecólogo del programa de patología Cervical de la Liga Santandereana de Lucha contra el Cáncer en Bucaramanga. Miembro del Comité Coordinador del Comité Santandereano Interinstitucional para la prevención y el diagnóstico precoz del Cáncer de Cérvix. Bucaramanga.

Profesor del Departamento de Ginecobstetricia de la Universidad Industrial de Santander, Bucaramanga. núa generando cifras importantes de morbilidad y mortalidad (1, 3). A pesar de ser susceptible de prevención, diagnóstico precoz y tratamiento oportuno y curativo, seguimos registrando tasas altas de morbilidad y mortalidad por cáncer de cérvix, indicativos del subdesarrollo de nuestro sistema de salud.

Bucaramanga y su área de influencia ocupa el primer lugar a nivel nacional en tasas de mortalidad por cáncer de cérvix. Tenemos zonas geográficas de alta incidencia y baja prevención especialmente en regiones de El Cesar y el Magdalena Medio y empezamos a sentir el peso de las fallas en el sistema tradicional y masivo de detección precoz: la citología.

Los resultados del presente trabajo y de otros recientemente publicados sobre el tema sirvieron de base para modificar el esquema de detección planteado por el plan nacional de cáncer, en el sentido de realizar búsqueda intencionada de neoplasia cervical en un grupo de mujeres con citología clase II (PAP II).

\section{MATERIALES Y ME TODOS}

Durante los meses comprendidos entre septiembre de 1987 y agosto de 1989 se les practicó colposcopia a 355 pacientes con citología PAP II en la Liga Santandereana de Lucha contra el Cáncer de la ciudad de Bucaramanga. Cerca de la mitad de los casos se vieron en los 6 primeros meses e incluyeron citologías PAP II independientemente de las observaciones anotadas por las citotecnólogas y los patólogos. En los meses restantes se estudiaron principalmente pacientes cuyas citologías tenían obser- 
vaciones como frotis inflamatorio o hemorrágico, atipias coilocíticas, metaplasia escamosa atípica, atipias severas. Se tomaron biopsias de cérvix cuando se encontraron imágenes colposcópicas sugestivas de neoplasia cervical. En la primera parte del estudio se hicieron revisar nuevamente las láminas de las citologías por un patólogo, el cual desconocía el resultado que se había informado previamente y que en la mayoría de los casos era asignado por citotecnólogas.

Para el análisis de resultados se dividió la muestra en tres grupos:

1. PAP II simple

2. PAP II inflamatorio $y / o$ hemorrágico

3. PAP II con atipias severas, atipias coilocíticas o metaplasia escamosa atípica.

La característica de inflamatorio y/o hemorágico se asignó a las citologías que tuvieran escrita dicha observación en forma explícita y a las que tuvieran $3+o$ más de leucocitos y/o hematíes.

Como una investigación complementaria se revisó la fecha de la última citología negativa (generalmente PAP II) en las pacientes a quienes se les diagnosticó Neoplasia Intraepitelial Cervical III (NIC III) y carcinoma invasor, en la consulta de Cérvix de la Liga Santandereana de Lucha Contra el Cáncer durante los últimos $31 / 2$ años. Se calculó el porcentaje de casos sin citología previa y con citología reciente negativa (últimos dos años).

\section{RESULTADOS}

En la Fig. 1 se muestran los diagnósticos de las 355 mujeres incluidas en el estudio. Asumimos como negativos para neoplasia cervical los casos en que se tomó biopsia por no encontrar imágenes colposcópicas sospechosas. La incidencia de neoplasia cervical fue de $33 \%$ y aunque predomina la displasia leve o NIC I (19.4\%), no es despreciable el porcentaje con lesiones mayores $(12.5 \%)$.

La Tabla 1 distribuye a las pacientes en subgrupos, evidenciando una mayor frecuencia de neoplasia cervical en las citologías inflamatorias y/o hemorrágicas $(37 \%)$ y en las citologías con atipias marcadas $(66 \%)$, con relación al grupo de PAP II simple $(23 \%)$.

En la Tabla 2 se comparan las pacientes de la liga con un grupo de pacientes del Instituto Colombiano de Seguros Sociales (ISS) remitidas y evalua- das por el autor. La mayoría de estas últimas tenían observaciones de inflamación o atipias marcadas.

FIGURA 1

\section{NEOPLASIA CERVICAL EN MUJERES CON CITOLOGIA CLASE II}

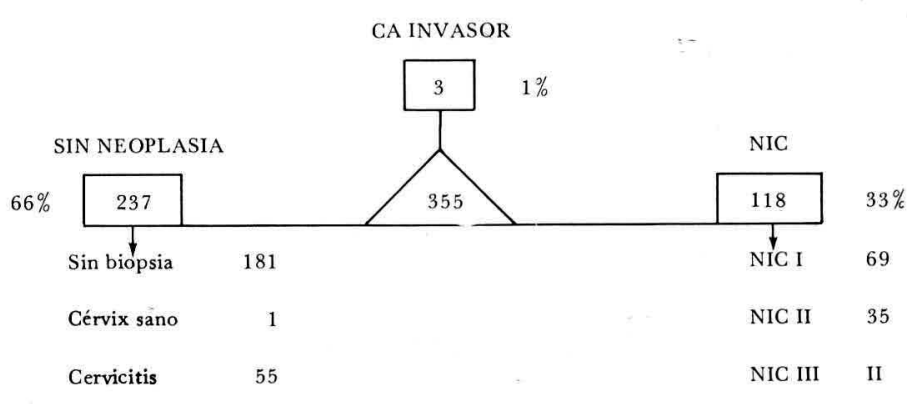

TABLA 1

\section{NEOPLASIA CERVICAL EN MUJERES CON DIFERENTES GRUPOS \\ DE CITOLOGIA CLASE II \\ $\mathrm{N}=355$}

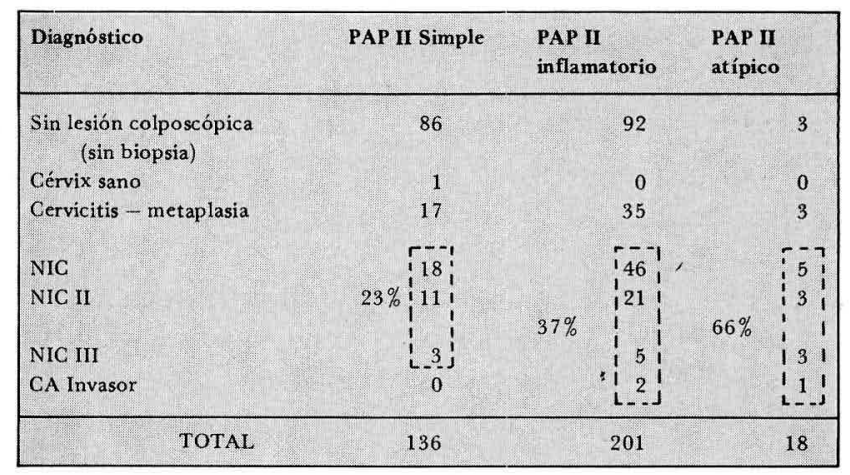

TABLA 2

\section{NEOPLASIA CERVICAL EN DIFERENTES GRUPOS DE MUJERES CON PAP II}

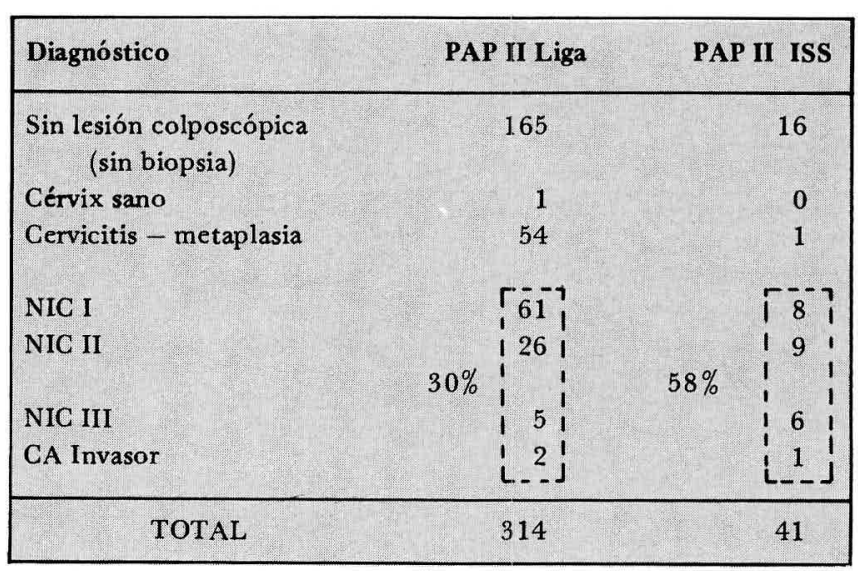


La reclasificación de las láminas de citología por el patólogo en las primeras 124 pacientes del estudio se muestra en la Fig. 2, especificando la incidencia de neoplasia cervical en los grupos de citología Clase I, Clase II y Clase III.

\section{FIGURA 2}

\section{NEOPLASIA CERVICAL EN MUJERES CON PAP II Y RECLASIFICACION DE LA CITOLOGIA POR PATOLOGO}

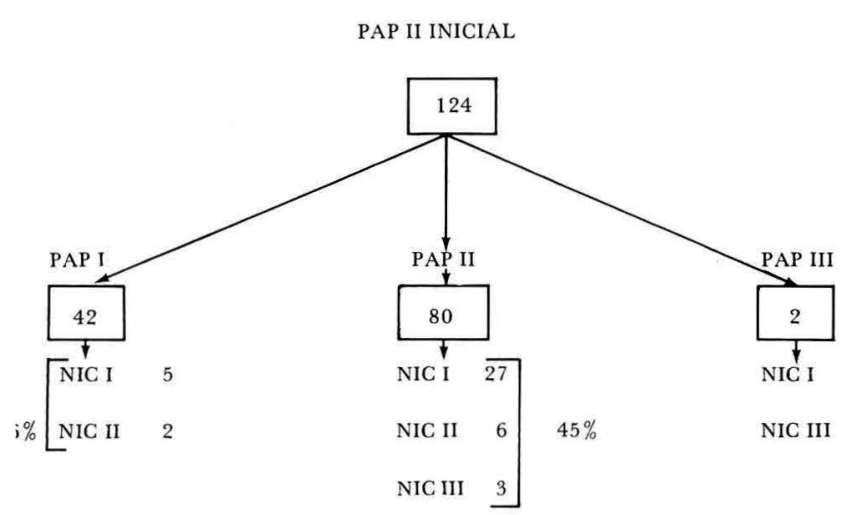

Durante los últimos $31 / 2$ años se diagnosticaron en la consulta de cérvix de la Liga Santandereana de Lucha Contra el Cáncer 354 casos nuevos de NIC III (displasias severas y carcinomas in situ) y 87 casos nuevos de carcinoma invasor, para un total de 441 casos. 380 Tenían consignado el dato de la citología anterior a la normal, de las cuales 180 (47\%) tenían citología negativa en los últimos dos años y $144(38 \%)$ no se habían tomado antes una citología. Se apreció un cambio significativo entre los períodos 1986-1987 y 1988-1989 puesto que un mayor número de casos tenían citología reciente negativa en el segundo período, a la vez que disminuyó el número de casos con citología de primera vez (Tablas 3 y 4). Este cambio fue más evidente para los carcinomas invasores.

\section{DISCUSION}

Los objetivos de un buen programa de control del cáncer de cérvix deben apuntar hacia su prevención y diagnóstico precoz, reduciendo a un mínimo los casos de carcinomas invasores y aumentando el diagnóstico y tratamiento de la neoplasia intraepitelial. Dos pilares dan eficiencia al programa: cobertura amplia y método de detección eficaz. Somos conscientes que la cobertura es insuficiente en Colombia porque seguimos diagnosticando carcinomas avanzados en mujeres sin citología previa. Pero empiezan a preocuparnos los carcinomas en mujeres con citología reciente negativa, los cuales tam- bién son frecuentes y van ganando proporción a medida que la cobertura aumenta.

TABLA 3

\section{INTERVALO ENTRE CITOLOGIA NEGATIVA (PAP II) Y DIAGNOSTICO DE NIC III $\mathrm{N}=303 *$}

\begin{tabular}{|c|c|c|}
\hline Tiempo (meses) & Período 1986-87 & Período $1988-89$ \\
\hline$\leqslant 12$ & & \\
\hline $13-24$ & 26 & 29 \\
\hline $25-60$ & 17 & 16 \\
\hline$>60$ & 4 & 7 \\
\hline Primera vez & $38 \% \leftarrow 60$ & $28 \% \leftarrow 41$ \\
\hline TOTAL & 158 & 145 \\
\hline
\end{tabular}

* Se excluyeron 51 casos porque no tenían el dato de la citología anterior.

TABLA 4

INTERVALO ENTRE CITOLOGIA NEGATIVA (PAP II) Y DIAGNOSTICO DE CA INVASOR $\mathrm{N}=77^{*}$

\begin{tabular}{|lrc|}
\hline Tiempo (meses) & Período 1986-87 & Período 1988-89 \\
\hline$\leqslant 12$ & $16 \%{ }^{3}$ & 15 \\
$13-24$ & 2 & 1 \\
$25-60$ & 1 & 7 \\
$>60$ & $75 \% \leftarrow 24$ & $19-42 \%$ \\
Primera vez & & \\
\hline TOTAL & & \\
\hline
\end{tabular}

* Se excluyeron 10 casos porque no tenían el dato de la citología anterior.

En países donde la citología se hace de rutina a la mayoría de las mujeres en riesgo, cerca de la mitad de los carcinomas invasores aparecen con citologías recientes negativas $(4-6)$ y para ellos el problema ya no es la cobertura sino el aumento de la eficacia del método de detección masivo. Ha cambiado entonces el concepto de la "atipia benigna" en la citología y el PAP II que antes se consideraba negativo empieza a tener importancia como citología que no es normal. Diferentes estudios han mostrado una proporción no despreciable de neoplasia cervical (generalmente intraepitelial) en mujeres con citología clase II $(7-13)$ y han sugerido el estudio colposcópico de las mujeres con citología II 
inflamatoria, con atipia coilocítica o metaplasia escamosa atípica, o complementar la citología con otro método de detección masiva como la cervigrafía (7).

La incidencia de neoplasia cervical asociada a citología PAP II en el presente estudio (33\%) es similar a la reportada por otros autores y corrobora la utilidad de la colposcopia en dichas pacientes. No obstante, este es un procedimiento más costoso que la citología y no está al alcance de todos los servicios de salud; y cuando contamos con él, se nos plantea un problema diferente: la gran mayoría de las citologías en nuestro medio se informan como clase II. En la Liga Santandereana de Lucha Contra el Cáncer por ejemplo, el $96.8 \%$ de las citologías leídas en 1986 correspondió a esta clase (14), mientras que la citología clase I representó solamente el $1.2 \%$. Tendríamos entonces que hacerle colposcopia al $98.8 \%$ de las mujeres que se toman la citología, lo cual resulta imposible.

Tres estrategias permitirían hacer un uso más selectivo de la colposcopia.

1. Concientizar y actualizar a citotecnólogas y patólogos sobre la importancia de que el PAP I alcance la frecuencia que le corresponde, teniendo criterios más estrictos para clasificar el PAP II. En otros países la frecuencia de citología clase II oscila entre 1.8 y $32 \%(8,10,12)$ y no habría razón para que nosotros tengamos un $97 \%$. De las 124 láminas reclasificadas por un patólogo en el presente estudio, 42 (34\%) se catalogaron como PAP I y en ellas la incidencia de neoplasia cervical fue menor y de menor grado (Fig. 2).

2. Seleccionar para colposcopia los grupos de PAP II con mayor riesgo de neoplasia cervical: inflamatorias, con atipias coilocíticas, atipias severas o metaplasia escamosa atípica. Otros trabajos han informado de este mayor riesgo y los resultados del presente estudio lo confirman: $23 \%$ de neoplasia cervical en el PAP II simple, $37 \%$ en el inflamatorio y/o hemorrágico y $66 \%$ en las atipias marcadas.

3. Recurrir a otro método de detección masivo como la cervigrafía, que complementa la citología y puede detectar 5 veces más neoplasia cervical que aquella (7). Esto no es práctico para los países pobres por carencia del recurso y por el costo que tendría.
4. Repetir con mayor frecuencia la citología en mujeres con clase II y espaciar a más de un. año el intervalo solamente en los casos de citología clase I.

El Comité Interinstitucional de Santander para la prevención y diagnóstico precoz del cáncer de cérvix ha incluido en su programa 3 de las 4 alternativas expuestas: capacitación y actualización de citotecnólogas y patólogos; selección de grupos de mayor riesgo para colposcopia y toma anual de la citología cuando el resultado es clase II.

Llama la atención la alta incidencia de neoplasia cervical en el grupo de mujeres con citología PAP II del ISS (58\%). Ello puede explicarse porque la mayoría tenían extendidos inflamatorios o con atipias severas y no corresponden a un muestreo al azar. Sin embargo, debe resaltarse la baja frecuencia de citologías anormales en dicha entidad. El último boletín epidemiológico de la seccional de $\mathrm{Bu}$ caramanga reporta un $7 \%$ mientras que para la Liga Santandereana de Lucha Contra el Cáncer la cifra es de $20 \%$ (14) y Arango reporta $17 \%$ y $15 \%$ en poblaciones de Antioquia y Boyacá (15).

El hallazgo de citologías recientes normales en pacientes a quienes se les diagnóstica NIC III o carcinoma invasor es un reflejo indirecto de los falsos negativos de la citología, pues sabemos que la mayoría de estas lesiones tienen evolución lenta. La cifra de $56 \%$ para NIC III y $36 \%$ para carcinoma invasor de la consulta de la Liga en los últimos dos años es significativa y aumentará a medida que se amplie la cobertura del programa.

\section{CONCLUSIONES}

Los resultados obtenidos confirman para nuestro medio los hallazgos en otras poblaciones y nos plantean la necesidad de incluir al menos un grupo de nuestras mujeres con citología II en el protocolo de manejo de la citología anormal. También nos alertan sobre el intervalo con que se debe practicar dicha citología y que no debe asimilarse al de la citología clase I; 3 años parece mucho tiempo aunque se tengan dos citologías consecutivas, especialmente si queremos diagnosticar neoplasia intraepitelial. Finalmente, una citología clase II no brinda la suficiente garantía en el control del tratamiento conservador de la neoplasia cervical y no obvia la necesidad de practicar al menos una colposcopia. 


\section{BIBLIOGRAFIA}

1. RESTREPO, H.; GONZALEZ, J.; ROBERTS, E.; LITVACK, J. Epidemiología y control del cáncer del cuello uterino en América Latina y el Caribe. Boletín OPS 1987: 102: 578-91.

2. GALlego, M.G.; URIBE, D.J. Análisis del NIC en el Hospital Universitario San Vicente de Paul 1970-1987. Rev. Col. Obstet. Ginecol 1988: 39: 179-84.

3. PINILLA, E.; URIBE, D.J.; GONZALEZ, G. Cáncer de cérvix IB. Análisis de 110 casos. Rev. Col. Obstet. Ginecol. 1988; 39: 186-90.

4. PETERS, R.K.; THOMAS, D.; SHULTIN, G.; HENDERSON, B. Invasive squamous cell carcinoma of the cervix after recent negative cytologic test results. A distinct subgrup? Am. J. Obstet. Gynecol 1988; 158: 926-35.

5. BEARMAN, M.D.; MAC MILLAN, J.P.; CREASMAN, W.T. Papanicolaou smear story of patients developing cervical cancer: An assessment of screening protocolos. Obstet. Gynecol. 1987: 89: 151-5.

6. WALTER, E.M.; COOPER, P. A retrospective review of cervical citology in women developing invasive squamous cell carcinoma. Br. J. Obstet. Gynecol 1983; 90: 1087-91.

7. TAWA, K.; FORSYTHE, A.; SALATZ, A. et al. A comparison of the Papanicolaou smear and the cervigram: Sensitivity, specificity, and cost analysis. Obstet Gynecol 1987; 156: 62831.
8. NOUMOFF, J.S. Atypia in the cervical citology as a risk factor for the intraepitelial neoplasia. Am. J. Obstet. Gynecol 1987; 156: 628-31.

9. SHINGLEXTON, H.M.; GORE, H.; AUSTIN, J.M. Outpatient evaluation of patient with atypical Papanicolaou smears. Contribution of endocervical curettage. Am. J. Obstet. Gynecol. 1976 ; 126 : 122-28.

10. HULKA, B.S. Citologic and histologic outcome following in atypical cervical smear. Am. J. Obstet Gynecol 1968; 101: 190-99.

11. REITER, R.C. Management of inicial atypical cervical citology: A randomized, prospective Study. Obstet. Gynecol 1986; 68: $237-40$.

12. DAVIS, G.L.; HERNANDEZ, E.; DAVIS, L.J.; MIYAZAWA, $\mathrm{K}$. Atypical squamous cells in Papanicolaou smears. Obstet Gynecol 1987; 69: 43-6.

13. MESA, C.M.; ESPARZA, D.C.A. Diagnóstico precoz de cáncer de cérvix. Rev. Col. Obstet. Gynecol 1989; 40: 123-34.

14. SILVA, P.P.I. Citología vaginal: Controversias y perspectivas. Médicas UIS 1988; 2: 187-95.

15. ARANGO, J.F.; BERNAL, L.S.; ECHEVARRIA, C.I. y col. Carcinoma de cérvix. Medicina UPB 1984; 4: 57-73. 